Hans Friberg

Niklas Nielsen

\section{Therapeutic hypothermia and coronary angiography are mandatory after out-of-hospital cardiac arrest: No}

Received: 1 May 2014

Accepted: 2 May 2014

Published online: 22 May 2014

(C) Springer-Verlag Berlin Heidelberg and ESICM 2014

For a contrasting viewpoint, please go to

doi:10.1007/s00134-014-3327-3.

H. Friberg $(\varpi) \cdot$ N. Nielsen

Department of Anaesthesia and Intensive Care Medicine, Skåne

University Hospital, Lund University, 22185 Lund, Sweden

e-mail: hans.a.friberg@gmail.com

Sudden out-of-hospital cardiac arrest is a major health problem throughout the world and in spite of increased awareness in society and improved pre-hospital and hospital care, overall survival remains around $10 \%[1,2]$. An impressive effort to create a prospective populationbased registry covering all out-of-hospital cardiac arrest patients in greater Paris was made and the results from the first 2 years are published in this issue of the journal [3]. The high quality registry study excluded cardiac arrest of obvious non-cardiac aetiology resulting in 3,816 patients in whom a resuscitation attempt was made, which translates into a yearly incidence of $0.6 \%$ per inhabitant, similar to what has previously been reported [4]. Admission rate to hospital was impressively high, $35 \%$, while $8 \%$ were discharged alive. The size and quality of this registry make it unique, including the systematic collection of pre-hospital and in-hospital background and treatment data. A retrospective control was performed in a sample of intensive care units (ICUs) indicating that an outstanding $99 \%$ of all cardiac arrest patients admitted alive were identified during the study period [3], which is notably higher than in previous reports [5]. It is encouraging that the pre-hospital factors strongly associated with survival to discharge remain the same as earlier identified-initial shockable rhythm, younger age, bystander CPR and cardiac arrest in a public place-suggesting ways to improve pre-hospital performance by educating more lay people, deployment of defibrillators and by engaging fire-fighters, police, taxi drivers etc.

The recently published target temperature management after cardiac arrest trial (TTM trial) included basically the same patient group as captured in the present French study [6]. The TTM trial randomly assigned 950 out-ofhospital cardiac arrest patients of cardiac aetiology to a target temperature of either 33 or $36{ }^{\circ} \mathrm{C}$ with no difference in survival (Fig. 1) or neurological outcome between groups. Compared to the present registry study, patients in the TTM trial had an early angiography performed approximately as often $(63 \%$ versus $58 \%$ ) while the use of temperature control differed (100\% versus $58 \%$ ). In the present study, $22 \%$ of patients admitted alive to hospital were eventually discharged alive; almost all (96\%) with a good neurological outcome. Haemodynamic failure was considered to be the cause of death in a majority of patients $(55 \%)$ with neurological cause as the runner-up $(43 \%)$. These results differ from other published studies [7, 8] including those from the TTM trial, where a majority of deaths were considered to be of a neurological cause [6].

As in the present registry study, TTM sites did not have a common post-cardiac arrest treatment protocol but all adhered to current treatment guidelines (except for choice of temperature). Approximately half of the patients in the TTM trial survived, the large majority with a good neurological outcome at 180 days, evaluated with rather crude but established outcome measures during a face-to face follow-up. In-hospital mortality among patients admitted alive after out-of-hospital cardiac arrest thus remains high, although a doubling of in-hospital survival has been described in the last decade [9] thanks to the introduction of post-cardiac arrest care bundles including 
Fig. 1 Kaplan-Meier estimates for time to death in the TTM trial intervention groups. From Medicine, Nielsen et al, Targeted Temperature Management at $33^{\circ} \mathrm{C}$ versus $36^{\circ} \mathrm{C}$ after Cardiac Arrest, Vol 369, Page 2197-2206. Copyright (C) (2013) Massachusetts Medical Society. Reprinted with permission New England Journal of

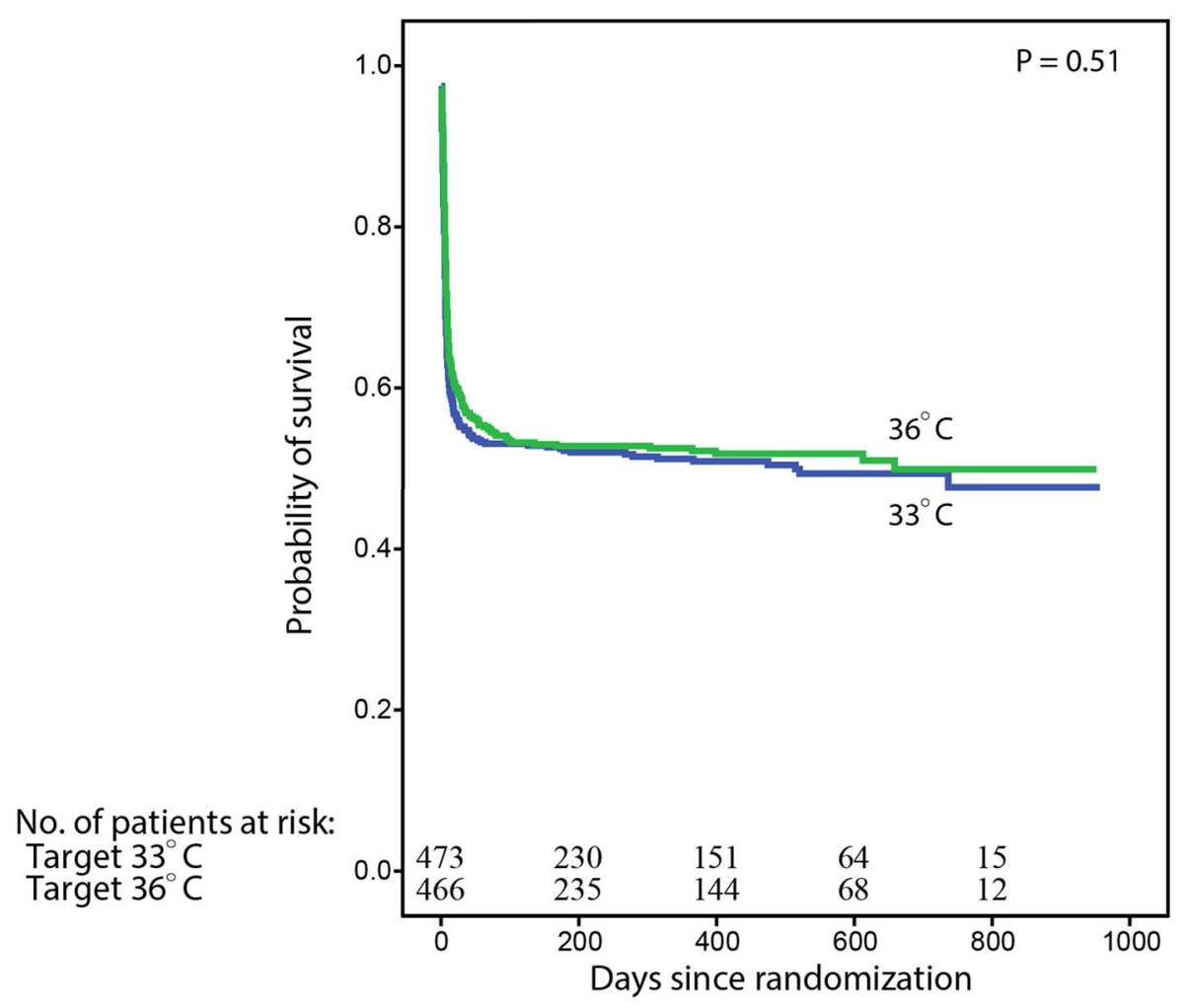

controlled temperature, angiography, improved ICU-care in general and possibly increased enthusiasm for the patient group.

Evidence-based medicine should be the foundation as we move forward in order to identify possible interventions to further improve in-hospital care and outcome after cardiac arrest. It is also important that we use the same principles when recommending which patient groups should receive interventions already introduced in clinical practice. For instance, should we offer hypothermia and coronary angiography to all patients that are admitted to hospital after out-of-hospital cardiac arrest?

Targeted temperature management and early angiography are two potentially important interventions for the cardiac arrest survivor. Regarding the choice of 33 or $36^{\circ} \mathrm{C}$ as target temperature, the clinician can choose either on the basis of the results of the TTM trial. International guideline experts suggest that clinicians stay with $33{ }^{\circ} \mathrm{C}$ but accept that some may use $36{ }^{\circ} \mathrm{C}$ until a proper guideline process has been undertaken [10]. However, all 36 TTM sites in ten countries have changed to $36{ }^{\circ} \mathrm{C}$ according to a "less-invasive" principle, commonly acknowledged in evidence-based medicine, and endorsed in a recent $B M J$ editorial [11]. We thus argue against hypothermia to $33{ }^{\circ} \mathrm{C}$ but for controlled temperature management at $36{ }^{\circ} \mathrm{C}$ in a majority of out-of-hospital cardiac arrest patients of cardiac origin. We should also consider the possibility that the temperature may not be the most crucial part of post-cardiac arrest care, but rather the bundle of care including controlled temperature and delayed prognostication that comatose cardiac arrest survivors are offered in modern intensive care medicine [12].

There is no randomized controlled trial evaluating the effect of an early angiography and percutaneous coronary intervention (PCI) in patients with cardiac arrest, and published results from retrospective observation studies are conflicting $[13,14]$. On the basis of the same lessinvasive principle, we argue against early angiography in all comatose out-of-hospital cardiac arrest survivors of cardiac origin until more evidence is provided [15]. We argue that early angiography should be limited to the approximately one-third of cardiac arrest patients with ST-elevation myocardial infarction (STEMI), signs of ongoing ischemia (dynamic ST-depression), cardiogenic shock or recurrent ventricular arrhythmias.

Conflicts of interest Hans Friberg-Bard Medical (lecture fee), Niklas Nielsen-Bard Medical (lecture fee). 


\section{References}

1. Sasson C, Rogers MA, Dahl J, Kellermann AL (2010) Predictors of survival from out-of-hospital cardiac arrest: a systematic review and metaanalysis. Circ Cardiovasc Qual Outcomes 3:63-81

2. Kitamura T, Iwami T, Kawamura T, Nitta M, Nagao K, Nonogi $H$, Yonemoto N, Kimura T, Japanese Circulation Society Resuscitation Science Study G (2012) Nationwide improvements in survival from out-ofhospital cardiac arrest in Japan. Circulation 126:2834-2843

3. Bougouin W, Lamhaut L, Marijon E et al (2014) Characteristics and prognosis of sudden cardiac death in Greater Paris: population-based approach from the Paris Sudden Death Expertise Center (Paris-SDEC). Intensive Care Med. doi: 10.1007/s00134-014-3252-5

4. Strömsöe A, Afzelius S, Axelsson C, Södersved Källestedt ML, Enlund M, Svensson L, Herlitz J (2013) Improvements in logistics could increase survival after out-of-hospital cardiac arrest in Sweden. J Intern Med 273:622-627

5. Strömsöe A, Svensson L, Axelsson ABBB, Göransson K, Todorova L, Herlitz J (2013) Validity of reported data in the Swedish Cardiac Arrest Register in selected parts in Sweden. Resuscitation 84:952-956
6. Nielsen N, Wetterslev J, Cronberg T, Erlinge D, Gasche Y, Hassager C, Horn J, Hovdenes J, Kjaergaard J, Kuiper M, Pellis T, Stammet P, Wanscher M, Wise MP, Aneman A, Al-Subaie N,

Boesgaard S, Bro-Jeppesen J, Brunetti

I, Bugge JF, Hingston DH, Juffermans NP, Koopmans M, Køber L, Langørgen J, Lilja G, Møller JV, Rundgren M, Rylander C, Smid O, Werer C, Winkel P, Friberg H (2013) Targeted temperature management at $33^{\circ} \mathrm{C}$ versus $36^{\circ} \mathrm{C}$ after cardiac arrest. N Engl J Med 369:2197-2206

7. Laver S, Farrow C, Turner D, Nolan J (2004) Mode of death after admission to an intensive care unit following cardiac arrest. Intensive Care Med 30:2126-2128

8. Dragancea I, Rundgren M, Englund E, Friberg H, Cronberg T (2013) The influence of induced hypothermia and delayed prognostication on the mode of death after cardiac arrest. Resuscitation 84:337-342

9. Fugate JE, Brinjikji W, Mandrekar JN, Cloft HJ, White RD, Wijdicks EF, Rabinstein AA (2012) Post-cardiac arrest mortality is declining: a study of the US National Inpatient Sample 2001 to 2009. Circulation 126:546-550

10. Jacobs I, Nadkarni V (2013) Targeted temperature management following cardiac arrest - an update. ILCOR update
11. Bernard S (2014) Inducing hypothermia after out of hospital cardiac arrest. BMJ 348:g2735

12. Sunde K, Pytte M, Jacobsen D, Mangschau A, Jensen LP, Smedsrud C, Draegni T, Steen PA (2007)

Implementation of a standardised treatment protocol for post resuscitation care after out-of-hospital cardiac arrest. Resuscitation 73:29-39

13. Dumas F, Cariou A, Manzo-Silberman S, Grimaldi D, Vivien B, Rosencher J, Empana J-P, Carli P, Mira J-P, Jouven $X$, Spaulding C (2010) Immediate percutaneous coronary intervention is associated with better survival after outof-hospital cardiac arrest: insights from the PROCAT (Parisian Region Out of hospital Cardiac ArresT) registry. Circ Cardiovasc Interv 3:200-207

14. Bro-Jeppesen J, Kjaergaard J, Wanscher M, Pedersen F, Holmvang L, Lippert F, Møller J, Køber L, Hassager C (2012) Emergency coronary angiography in comatose cardiac arrest patients: do real-life experiences support the guidelines? Eur Heart J Acute Cardiovasc Care 1:291-301

15. Nielsen N, Kjaergaard J (2013) Should out-of-hospital cardiac arrests patients without ST-elevation go immediately to the cardiac catheterisation laboratory? Resuscitation 84:139-140 